\title{
Reliability and validity of the attitude towards research scale for a sample of industrial psychology students
}

\author{
Sanet van der Westhuizen
}

\begin{abstract}
The study investigated the reliability and validity of the Attitudes towards Research Scale for a South African sample. A cross-sectional survey design was used and a convenience sample of postgraduate students in industrial psychology $(N=185)$ participated in the study. A biographical scale and the Attitudes towards Research Scale were administered. Confirmatory factor analysis, exploratory factor analysis, correlations and descriptive statistics were used to analyse the data. The results indicated that none of the previously suggested one-factor, five-factor or three-factor structures of the Attitudes towards Research fitted the data well. A revised three-factor structure consisting of positive outlook on research, anxiety and difficulty, and the usefulness of research fitted the data acceptably. Students in this sample displayed positive attitudes towards research, regarded it as beneficial to them in their profession, but deemed it to be somewhat difficult and displayed moderate levels of anxiety about it.
\end{abstract}

\section{Keywords}

Attitudes, postgraduate students, research anxiety, research methodology

Research could be seen to be at the centre of all activities of psychologists (Howitt \& Cramer, 2014). Scholars of Psychology should be able to tackle South Africa's problems through research that is responsive to all of society's needs (International Education Association of South Africa [IEASA], 2009). One of the primary tasks of Industrial Psychologists in particular is to generate new knowledge and solutions through research in order to address the critical challenges and socio-economic issues stemming from the contexts in which organisations are located (Schreuder \& Coetzee, 2010). Increasing research development, with a particular focus on postgraduate degrees, is therefore an integral part of the Department of Higher Education and Training's (DHET) strategic plan (DHET, 2012). Hence, more emphasis should also be placed on increasing the research capacity of prospective psychologists and industrial psychologists at postgraduate level in universities.

It is proposed that researcher development should include behavioural, attitudinal, and intellectual components (Evans, 2012). Evans (2011) also contends that the attitudinal component of researcher development is of primary importance and fundamental to researchers' behavioural and intellectual development. However, Evans (2012) posits that the attitudinal component of researcher development has been largely overlooked. One reason for this oversight could be the paucity of instruments to measure students' attitudes towards research (ATR; Papanastasiou \& Schumacker, 2014). The purpose of this study was therefore to determine the reliability and validity of the ATR scale (Papanastasiou, 2005) for a South African sample. 


\section{Students' ATR}

Experience in teaching research methods courses for almost 10 years and evidence reported in the literature suggest that most students harbour negative feelings about the prospects of completing a research methodology course during their studies (Earley, 2014). These negative feelings or attitudes tend to include feeling anxious, nervous, and overwhelmed at the outset of a research methodology course (Earley, 2014; Papanastasiou \& Zembylas, 2008; Schulze, 2010; Walker, 2010). It would seem that if given the choice, students would avoid such a course in research methodology altogether (Selaledi, 2009). Earley (2014) acknowledges that no causal factors have thus far been identified to explain why students are not receptive to research methodology courses. One aspect might be that students tend to dread the quantitative data analysis as part of research. In this regard, Laher, Israel, and Pitman (2007) reported that their biggest challenge in presenting a programme on research design and analysis to undergraduate students in psychology were to combat the statistics anxiety of students. Coetzee and Van der Merwe (2010) also confirmed that students in Industrial Psychology find statistics to be difficult, technical and complicated to master. No previous research could be found that investigated if students' ATR may differ based on studying at a residential university as opposed to a distance education university. Schulze (2009) did, however, acknowledge that including more socio-constructivist principles in a postgraduate research methodology module at a distance education institution may improve students' achievement as well as attitude. Some of these principles would include using blended learning strategies to enable lecturers to model appropriate behaviour, providing more 'practical hands-on research experience', stimulating online discussions and providing more opportunities to work together in a team (Schulze, 2009). Concurring with this, Gelso, Baumann, Chui, and Savela (2013) stated that constructing an applicable training environment could impact graduate students' research attitudes. They suggest that the following aspects seem to have the greatest association with students' attitude, namely faculty modelling scientific behaviour, positively reinforcing students' scientific behaviour, allowing students to experience science as a partly social-interpersonal experience by working in teams, and 'teaching students that all research is flawed and limited' (Gelso et al., 2013). Van der Westhuizen (2014) found that students enrolled for an online research methodology module at a distance education institution were positive about research in general, deemed research to be important and useful for their career and professional life, but experienced a lot of anxiety about research at the onset of the course.

Anxiety and negative attitudes may serve as obstacles to learning, influence the amount of effort students are willing to put into learning a specific subject like research, or even influence their performance in a module (Papanastasiou, 2005). Similarly, it is also believed that having a more positive ATR will lead to intrinsic motivation to engage in research (Evans, 2011) - hence the importance of assessing and investigating students' ATR.

\section{The measurement of ATR}

Very few quantitative measurements of ATR in general have been developed thus far. In the past, it seems that researchers tended to use context-specific measures of students' ATR in, for instance, music (Dorfman \& Lipscomb, 2005), nursing (Halabi \& Hamdan-Mansour, 2010; Mehrdad, Salsali, \& Kazemnejad, 2008), medical school (Siemens, Punnen, Wong, \& Kanji, 2010), education (Ozturk, 2011), or agriculture (Rezaei \& Zamani-Miandashti, 2013). Some measures have been developed to investigate students' attitude towards specific research approaches like qualitative research (Roberts \& Povee, 2014b) or mixed methods research (Roberts \& Povee, 2014a). Papanastasiou (2005), however, developed a scale that 
measures ATR in general as a multidimensional construct consisting of five factors, namely the degree to which students regard research as useful for their profession, deem it to be relevant to their life in general, demonstrate positive attitudes towards it, experience anxiety about it, and find research methodology difficult. Papanastasiou (2005) confirmed the five-factor structure of the 32-item scale in a sample of 226 students who had completed a compulsory and introductory undergraduate course in research methodology at the University of Cyprus. The first factor, research usefulness for my career, with nine items, was regarded as the most important factor since it accounted for $18.92 \%$ of the total ATR scale variance.

The second factor, which was comprised of eight items, was termed research anxiety and accounted for $17.94 \%$ of the variance. The third factor, also with eight items, was labelled positive ATR and accounted for $15.42 \%$ of the variance. The fourth factor related to the use of research in students' personal life and was termed relevance to life. The four items of this factor accounted for $8.30 \%$ of the variance. The last factor, research difficulty, consisted of three items and accounted for $5.67 \%$ of the total variance. Research usefulness was positively correlated with relevancy to life and positive ATR. Research anxiety and difficulty as well as positive attitudes were positively correlated but research anxiety and difficulty were not related to research usefulness or relevance to life. Papanastasiou (2005) found Cronbach's alpha coefficients of .95 for the total scale and .92 for usefulness of research, .92 for research anxiety, .93 for positive attitudes, .77 for life relevancy, and .71 for research difficulty.

Walker (2010) performed a confirmatory factor analysis (CFA) of the ATR. He used various indicators of fit to determine how closely Papanastasiou's (2005) five-factor model represented the sample data. The sample included 204 students in a graduate education research methods course at a large university in the United States. Using maximumlikelihood estimation (MLE), he con- ducted a CFA to test a one-factor model, Papanastasiou's (2005) five-factor model, and finally a three-factor model. The threefactor model consisted of research use (10 items), negative attributes of research (4 items), and positive attributes of research ( 4 items). The results revealed that the one-factor model showed a weak fit overall $\left(x^{2}(d f)=2669.70(464) ; x^{2} / d f=5.82\right.$; comparative fit index $(C F I)=0.30$; Tucker-Lewis index $(T L I)=0.25$; standardized root mean square $(S R M R)=$ 0.58; root mean square error of approximation (RMSEA) $=0.15$ ). The five-factor model also did not fit the data adequately $\left(x^{2}(d f)=984.59 \quad(454) ; X^{2} / d f=2.17 ; \quad C F I=0.83\right.$; $\mathrm{TLI}=0.82 ; \quad S R M R=0.16 ; \quad \mathrm{RMSEA}=0.08)$. The three-factor model supported the sample data better and displayed good model fit in all the indices investigated except for the SRMR value $\left(X^{2}(d f)=247.05(132) ; X^{2} / d f=1.87 ; C F I=0.92 ; T L I=0.91\right.$; $S R M R=0.13 ;$ RMSEA $=0.07)$. Score reliability was conducted for the three-factor model, and the values found were 0.88 for research use, 0.82 for positive attributes of research, and 0.81 for negative attributes of research, indicating high internal consistency across the three subscales. Walker (2010) as well as Papanastasiou and Schumacker (2014) recommended that the ATR scale should be used in samples from other countries to test for its equivalence in different contexts and student groupings as well as its properties of measurement invariance. No study could be found that examined the reliability and validity of the ATR in a South African sample. The purpose of this study was therefore to determine the reliability and validity of the ATR scale for a South African sample. 


\section{Method}

\section{Participants}

A convenience sampling strategy was used and 185 students who were enrolled for a research methodology module at honours level in industrial psychology at a distance education institution participated in the study. Most of the students (74.6\%) in the sample were female, with ages vary- ing between 20 and 51 with a mean age of 32. The majority of the sample were Black (51.9\%) with the remaining students being White $(23.2 \%)$, Indian (7\%), and coloured (5.4\%).

\section{Instruments}

Participants completed a biographical section (i.e., gender, age, and race) and the ATR scale (Papanastasiou, 2005). The ATR scale consists of 32 items measuring five subdimensions, namely research usefulness, research anxiety, positive attitudes, relevance to life, and difficulty of research. The items are listed on a seven-point Likert-type scale. Negatively worded items were reverse coded before any analyses were conducted. The psychometric properties as applied to a South African sample are established in this study.

\section{Procedure}

Students who had attended an annual discussion class for the research methodology module were asked to participate in the study. A measuring battery consisting of a consent form that needed to be signed, a biographical questionnaire, and the ATR were provided in hard copy to the students. After instructions were provided, students were given time to complete the battery and submit it to the presenters of the class.

\section{Ethical considerations}

Participation in the study was voluntary and students had the option to withdraw from the study at any time without fear of any consequences. They were informed of the purpose of the study, the confidentiality of the responses, and instructions for completing the questionnaire. They were also informed that their data may be used for publication. After giving their written informed consent, students completed the questionnaire manually. Ethical approval of the study was obtained from the University of South Africa.

\section{Data analysis}

Statistical analyses were conducted with the SPSS programme (SPSS 20.0, 2011) and Mplus (Muthén \& Muthén, 2012). CFA was conducted using structural equation modelling (SEM) to confirm the factorial models of the ATR. All CFA analyses were done using the MPlus programme. The maximum likelihood (ML) estimator was used to produce model parameters. The assumption indices were used to determine if the models fitted the data. The $\mathrm{X}^{2}$ statistic (CMIN), the CFI, the TLI, the RMSEA, and the RMSEA confidence intervals were used. The following cut-off scores were applied: CFI and TLI $\geq 0.90$ (Byrne, 2010; Hu \& Bentler, 1999); RMSEA < 0.05 to indicate good fit but values as high as 0.08 to represent reasonable errors of approximation (Byrne, 2006). Owing to the poor fit of the initial models tested in this research, further explorative analyses were conducted. The Kaiser-Meyer-Olkin measure of sampling adequacy (KMO) and Bartlett's test of sphericity were used to evaluate the suitability of factor analysis for this particular 
sample. Bartlett's test of sphericity should be statistically significant and KMO values between 0.80 and 0.90 are deemed to be outstanding (Field, 2009). The KMO for this sample was 0.85 and Bartlett's test of sphericity was statistically significant $(p<0.000)$, which provided sufficient justification to proceed with the factor analysis. Principal axis factoring was used to extract factors. Parallel analysis confirmed that three factors should be extracted. Lastly, promax rotation was applied in line with the recommendations of Conway and Huffcutt (2003). Items with factor loadings larger than 0.40 were retained in the factor structure was made that observed variables are measured on a continuous scale. A number of goodness-of-fit

Table 1. ATR construct validity.

\begin{tabular}{lrllllll}
\hline Model & $v^{2}$ & $d f$ & $p$ & CFI & TLI & RMSEA & $\begin{array}{l}\text { RMSEA 90\% } \\
\text { confidence } \\
\text { intann. }\end{array}$ \\
\hline $\begin{array}{l}\text { One-factor } \\
\text { Five-factor }\end{array}$ & 1810.53 & 464 & 0.00 & 0.53 & 0.46 & 0.13 & $0.12,0.13$ \\
Three-factor (Walker) & 580.15 & 249 & 0.00 & 0.83 & 0.80 & 0.08 & $0.07,0.09$ \\
\hline
\end{tabular}

ATR: attitudes toward research; $\mathrm{X}^{2}$ : chi-square; $d f$ degrees of freedom; $p$ : statistical significance; CFI: comparative fit index; TLI: Tucker-Lewis index; RMSEA: root mean square error of approximation.

Descriptive statistics were used (e.g., frequencies, means, modes, and standard deviations) to explore the data. Cronbach's alpha coefficients were used for assessing the internal consistency of the factors. Pearson's correlation coefficients were employed to determine the relationships between the variables. A confidence level of $95 \%(p \leq 0.05)$ was set to test for statistical significance. Effect size $(r)$ was used for assessing the practical significance of the correlation coefficients (Steyn, 1999). A cut-off point of 0.30 (medium effect) was set for the practical significance of the correlation coefficients (Cohen, 1988).

\section{Results}

\section{Validity of the ATR}

CFA was used to test the factorial models of the ATR as suggested by Walker (2010). Three models were proposed, namely, a one-factor model, the five-factor model of Papanastasiou (2005), and the three-factor model comprising research use, negative attributes of research, and positive attributes of research which, according to Walker (2010), showed an acceptable fit. The fit statistics are dis- played in Table 1.

Table 1 indicates that overall, the three models were unacceptable, indicating poor fit for all three models for this particular sample. Owing to a lack of theoretical evidence, it was decided not to run any alternative models at this stage. Instead, the researcher decided to revert to exploratory factor analysis (EFA) to further assess the construct validity of the ATR for this sample. Principal axis factoring was subsequently performed. Results revealed seven factors, explaining $56.46 \%$ of the variance. The resulting factor matrix was rotated to a simple structure using the promax rotation procedure. Item 4 cross-loaded on two factors and ltems 17, 20, 24, and 27 had factor loadings below 0.40 and were subsequently deleted. Four of the seven factors had only two or fewer items each and 
these items (8, 11, 14, 19, 23, 26, and 31) were therefore also removed from further analyses in line with what Papanastasiou (2005) had done in the original development of the scale. The factor analysis was performed again and it was specified that three factors should be retained in line with the guideline from parallel analysis. These three factors explained $49.37 \%$ of the variance. This rotated factor matrix is presented in Table 2 . To facilitate interpretation, the variables were ordered and grouped by size of loading.

Table 2. Rotated factor matrix of the ATR.

\begin{tabular}{llccc}
\hline Ite & Item statement & Factor & & \\
\cline { 3 - 5 } & & 1 & 2 & 3 \\
no. & & 0.95 & -0.02 & -0.0 \\
\hline 28 & I like research & 0.88 & 0.03 & 0.0 \\
18 & I love research & 0.88 & -0.03 & 0.0 \\
30 & Research is pleasant & 0.84 & -0.09 & 0.0 \\
13 & I am interested in research & 0.80 & 0.03 & -0.0 \\
3 & I enjoy research & 0.46 & 0.01 & 0.0 \\
29 & I am inclined to study the details of research & 0.21 & 0.82 & -0.1 \\
12 & Research makes me nervous (-) & -0.18 & 0.71 & -0.0 \\
16 & Research is stressful (-) & 0.09 & 0.69 & -0.1 \\
7 & Research scares me (-) & -0.09 & 0.68 & 0.0 \\
25 & Research is complicated (-) & -0.14 & 0.60 & 0.0 \\
5 & Research is difficult (-) & -0.02 & 0.58 & 0.18 \\
10 & I make many mistakes in research (-) & -0.04 & 0.53 & 0.19 \\
32 & Research is a complex subject (-) & -0.10 & 0.52 & 0.21 \\
6 & I feel insecure concerning the analysis of research data & 0.16 & 0.51 & -0.1 \\
9 & I find it difficult to understand the concepts of research & 0.07 & 0.42 & -0.0 \\
1 & Research makes me anxious (-) & 0.12 & 0.03 & 0.69 \\
21 & Research is useful to every professional & -0.05 & -0.01 & 0.62 \\
2 & Research should be taught to all students & 0.29 & 0.08 & 0.48 \\
22 & Knowledge from research is as useful as writing & 0.25 & 0.07 & 0.44 \\
15 & Most students benefit from research & & & \\
\hline
\end{tabular}

ATR: attitudes toward research.

The first factor was labelled positive outlook on research. The six items loading on this factor all related to how much students were interested in and tended to enjoy research. Factor 2 was identified as anxiety and difficulty and consisted of nine items. All of these items related to the degree to which students felt nervous or anxious about research and the degree to which they regarded research as complicated or found it difficult to understand the concepts of research. The third factor was labelled usefulness of research because its four items dealt with the degree to which students thought that research could be useful to them professionally, but also to their benefit in general. SEM was again used to confirm this revised factor structure of the ATR. The results of the EFA were used as input for Model 1. This model did not fit the data well and inspection of the modification indices suggested that Item 16 cross-loaded on both Factors 1 and 2. Item 16 was subsequently deleted and the model was fitted again as Model 2. The results are depicted in Table 3. As indicated in Table 3, Model 2 fitted the data acceptably ( $X^{2}=1803.42 ; d f=$ $171 ; p<0.05 ; \mathrm{CFI}=0.92 ; \mathrm{TLI}=0.90 ; \mathrm{RMSEA}=0.06$ ). 
Table 3. Construct validity of the revised ATR.

\begin{tabular}{llllllll}
\hline Model & $\mathrm{v} 2$ & $d f$ & $\mathrm{p}$ & $\mathrm{CFI}$ & $\mathrm{TLI}$ & $\mathrm{RMSEA}$ & $\begin{array}{l}\text { RMSEA 90\% } \\
\text { confidence } \\
\text { intonual }\end{array}$ \\
\hline Model 1 & 330.68 & 167 & 0.00 & 0.90 & 0.89 & 0.08 & $0.07,0.09$ \\
Model 2 & 278.16 & 149 & 0.00 & 0.92 & 0.90 & 0.06 & $0.05,0.08$ \\
\hline
\end{tabular}

ATR: attitudes toward research; $\mathbf{X}^{2}$ : chi-square; $d f$ degrees of freedom; $p$ : statistical significance; CFI: comparative fit index; TLI: Tucker-Lewis index; RMSEA: root mean square error of approximation.

The unstandardised freed factor loadings, the completely standardised freed factor loadings, the unstandardised measurement error, the completely standardised measurement error variances, and the $R^{2}$ for the items are reported in Table 4. From Table 4, it can be seen that although an acceptable model fit has been achieved, some items explain only a small portion of the latent variables. In this regard, Items A29, A1, $A 6$, and A32 may be less reliable indicators of positive outlook on research and anxiety and difficulty.

\section{Relationship between the factors and descriptive statistics for the sample}

Table 5 shows the correlations between the factors, Cronbach's alpha, and descriptive statistics of this revised ATR model. Table 5 indicates that all three factors yielded satisfactory internal consistency reliabilities. The Cronbach's alpha coefficient for the total scale was 0.82. Positive outlook on research and useful- ness of research correlated significantly (practical significance of large effect), but anxiety and difficulty did not correlate with any of the other factors. Students mostly agreed that research is useful to their profession and benefits them in general (the modal score for the sub-factor was 7, indicating that most students strongly agreed with statements like 'Research should be taught to all students' or 'Research is useful to every professional'). Students also displayed a positive outlook on research (the modal score for this sub-factor was also 7, indicating that most students strongly agreed with statements like 'I am interested in research' or 'I love research'). However, students found research to be moderately difficult and experienced some degree of anxiety about it (the modal score for this sub-factor was 4.78 , indicating that most students agreed with statements like 'Research is difficult' or 'Research makes me anxious'). The means and standard deviations could not be sensibly compared with results of other studies, because the scales were comprised of different items.

\section{Discussion}

As stated previously, the purpose of this study was to determine the reliability and validity of the ATR scale for a South African sample. The overall findings of the present study provided the first preliminary evidence of the validity and reliability of a revised version of the ATR for a South African sample. Similar to the findings of Walker (2010), a onefactor model and Papanastasiou's (2005) five-factor model did not fit the data well. However, contrary to the findings of Walker (2010), the three-factor structure composed of research use, negative attributes of research, and positive attributes of research did not fit the data well either. The reason for exploring alternative measurement models of the 
ATR instead of developing a new measure of students' ATR is twofold: the ATR has shown consistently strong psychometric properties in other international samples previously (Papanastasiou \& Schumacker, 2014) and developing a new measuring instrument is a

Table 4. Unstandardised and standardised parameter estimates.

\begin{tabular}{lllll}
$\begin{array}{l}\text { Unstandardised } \\
\text { freed factor }\end{array}$ & Standardised & Unstandardised & Standardised & $R^{2}$ \\
loadings & freed factor & measurement & measurement & \\
loadings & error & error variances & \\
\hline
\end{tabular}


Positive outlook on research

$\begin{array}{llllll}\text { A3 } & 1.00 & 0.77 & 0.91 & 0.41 & 0.59 \\ \text { A13 } & 1.07 & 0.85 & 0.57 & 0.28 & 0.72 \\ \text { A18 } & 1.28 & 0.89 & 0.56 & 0.21 & 0.79 \\ \text { A28 } & 1.25 & 0.94 & 0.29 & 0.12 & 0.88 \\ \text { A29 } & 0.67 & 0.49 & 1.85 & 0.76 & 0.24 \\ \text { A30 } & 1.21 & 0.88 & 0.54 & 0.22 & 0.78\end{array}$

Anxiety and difficulty

$\begin{array}{llllll}\text { A1 } & 1.00 & 0.45 & 2.16 & 0.80 & 0.20 \\ \text { A5 } & 1.12 & 0.50 & 2.09 & 0.75 & 0.25 \\ \text { A6 } & 1.00 & 0.44 & 2.36 & 0.81 & 0.19 \\ \text { A7 } & 2.07 & 0.78 & 1.57 & 0.40 & 0.60 \\ \text { A9 } & 1.34 & 0.56 & 2.21 & 0.69 & 0.31 \\ \text { A10 } & 1.04 & 0.51 & 1.71 & 0.74 & 0.26 \\ \text { A12 } & 2.33 & 0.89 & 0.79 & 0.20 & 0.80 \\ \text { A25 } & 1.45 & 0.60 & 2.10 & 0.64 & 0.36 \\ \text { A32 } & 0.92 & 0.37 & 3.03 & 0.87 & 0.13\end{array}$

Usefulness of research

$\begin{array}{llllll}\text { A2 } & 1.00 & 0.57 & 2.09 & 0.68 & 0.32 \\ \text { A15 } & 0.83 & 0.63 & 1.07 & 0.61 & 0.39 \\ \text { A21 } & 1.05 & 0.80 & 0.63 & 0.36 & 0.64 \\ \text { A22 } & 0.79 & 0.68 & 0.75 & 0.54 & 0.46\end{array}$

Table 5. Correlations, descriptive statistics, and Cronbach's Alpha coefficients of the revised ATR factors.

\begin{tabular}{|c|c|c|c|c|c|c|c|c|c|}
\hline & $N$ & Mode & $\begin{array}{l}\text { Std. } \\
\text { deviation }\end{array}$ & Skewness & Kurtosis & $\alpha$ & 1 & 2 & 3 \\
\hline $\begin{array}{l}\text { 1. Positive outlook on } \\
\text { research }\end{array}$ & 185 & 7 & 1.29 & -0.71 & 0.31 & .91 & 1 & & \\
\hline 2. Anxiety and difficulty & 185 & 4.78 & 1.14 & -0.14 & -0.66 & .82 & 0.02 & 1 & \\
\hline 3. Usefulness of research & 185 & 7 & 1.07 & -0.84 & 0.40 & .75 & $0.50^{*}+$ & $0.0 \approx$ & 1 \\
\hline
\end{tabular}

*Correlation is significant at the

0.01 level.

+Correlation is practically significant -

large effect.

complex process that requires a great investment of time, effort, and expertise. It thus seemed a worthwhile option to first explore alternative measurement models before expanding on such an elaborate task. Subsequently, a revised three-factor structure composed of usefulness of research, positive outlook on research, and difficulty and anxiety fitted the data acceptably. Upon inspection of the items that sorted together, this revised three-factor structure appeared to be more in line with Papanastasiou's (2005) original five-factor structure than with Walker's (2010) three-factor structure. All the items that loaded onto the positive outlook on research factor also loaded onto the original positive ATR factor of Papanastasiou (2005). Similarly, all the items that loaded onto the usefulness of research factor also loaded onto the original research usefulness for 
profession factor of Papanastasiou (2005). This revised three-factor structure differs from the five-factor structure of Papanastasiou (2005) in the sense that fewer items loaded onto the above-mentioned factors, none of the items of Papanastasiou's (2005) relevance to life factor loaded onto any of the revised three factors, and the items of research anxiety and research difficulty of Papanastasiou (2005) loaded onto one factor. One item on positive outlook on research and three items on anxiety and difficulty could however be seen as somewhat less reliable indicators of these factors. Nevertheless, the revised three factors displayed acceptable levels of internal consistency and compared well with the results obtained by Papanastasiou (2005) for the original five factors of the ATR. Anxiety and difficulty did not relate to students' positive outlook on research or the degree to which they regarded research as useful for their profession. This partially confirms the results of Papanastasiou (2005) who found that research anxiety did not correlate with research usefulness for profession, but correlated negatively with positive ATR. It therefore seems that these results provide preliminary evidence for the reliability and validity of a revised three-factor model of ATR. However, cross-validation with another sample is still needed to confirm the construct validity of this revised measurement model.

The results of this study also indicated that the industrial psychology students included in this study had positive ATR and deemed it to be useful to them professionally and in general. This contradicts the conclusions of Earley (2014) (after a synthesis of 89 studies on teaching and learning research methodology) that students typically fail to see the relevance of research for their field of study or their lives and that they have poor ATR. The industrial psychology students in this sample appeared to be interested in research and enjoyed it. Furthermore, they deemed research to be useful to their profession and were of the opinion that all students should be taught about research. This is more in line with the findings of Papanastasiou (2005) who also found that students deemed research useful for a profession and those of Rezaei and Zamani-Miandashti (2013), who found that agricultural students displayed highly positive ATR. Again, similar to the findings of Rezaei and Zamani-Miandashti (2013), the industrial psychology students in this sample dis- played moderate levels of anxiety and found research difficult to some degree. Earley (2014) also concluded that students are typically anxious or nervous about a course in research methodology and its difficulty. Since the factor of anxiety and difficulty does not correlate with the other two factors on the scale, it would seem that even though students display positive ATR and regard it as useful and beneficial, they can still feel somewhat anxious about it and deem it to be somewhat difficult, as was found by Van der Westhuizen (2014). Research anxiety can hinder students' learning (Earley, 2014) and is therefore worth addressing in a research methodology course.

\section{Conclusion}

Despite the fact that the industrial psychology students believe that research is a difficult subject, they are eager to learn more and tend to feel fairly positive about the value of research in their professional lives. Presenters of research methodology courses to psychology students could capitalise on these positive attitudes in order to further engage their students in conducting research and to help guide their instruction (Papanastasiou \& Schumacker, 2014). If students are already aware of the value of research for their profession, more time could be devoted to other aspects related to research methodology that students struggle with, for instance statistics. Psychology students who display positive ATR are also more likely to engage in future research as part of postgraduate studies 
or as part of their practice (Evans, 2011). Although results regarding the relationship between research methods achievement and ATR are inconclusive, it might be that high levels of negative predispositions towards research could hinder students' efforts from performing well in the course (Papanastasiou \& Schumacker, 2014). Students who might be 'at risk' could therefore be identified at the onset of the course in order to offer additional assistance to them.

The revised ATR (three-factor) appears to be valid and reliable for a sample of South African students, but should also be validated with other South African samples. Researchers could also investigate whether students in other fields of study have different ATR compared with students in industrial psychology or if students at a contact university have different ATR compared to students engaged in distance education (like the sample used in this study). Future research could also investigate how students' ATR develop or change over time and identify which factors influence or affect students' attitudes. One possibility might be the degree to which they dread the statistical component of research. Earley (2014) concluded that not much is known about the relationship between students' attitudes and their performance in research methodology courses. Future studies could investigate how and to what extent students' attitudes contribute towards their performance in research.

Since a sample of convenience was used, the results of this study cannot be generalised to other samples of students in South Africa. The sample size is also slightly less than what is required for CFA analysis (i.e., 185 instead of 200), and these results should therefore be interpreted with some caution.

\section{Funding}

This research received no specific grant from any funding agency in the public, commercial, or not-for-profit sectors. 


\section{References}

Byrne, B. M. (2006) Structural equation modelling with EQS: Basic concepts, applications and programming (2nd ed.). New York, NY: Taylor \& Francis Group.

Byrne, B. M. (2010) Structural equation modelling with AMOS (2nd ed.). New York, NY: Taylor \& Francis Group.

Coetzee, S., \& Van der Merwe, P. (2010) Industrial Psychology students' attitudes towards statistics. SA Journal of Industrial Psychology, 36(1), 843 (8 pp.).

Cohen, J. (1988) Statistical power analysis of the behavioural sciences (2nd ed.). Orland, CA: Academic Press.

Conway, J. M., \& Huffcutt, A. I. (2003) A review and evaluation of exploratory factor analysis practices in organizational research. Organizational Research Methods, 6, 147-168. Department of Higher Education and Training (DHET). (2012) Revised strategic plan 2010/11-2014/15.

DHET. Retrieved from http://www.dhet.gov.za/LinkClick.aspx?fileticket=k4aKtPbYHds\%3D\&ta bid=36

Dorfman, J., \& Lipscomb, S. D. (2005) Graduate music students' attitudes toward research. Journal of Music Teacher Education, 15, 31-42.

Earley, M. A. (2014) A synthesis of the literature on research methods education. Teaching in Higher Education, 19(3), 242-253.

Evans, L. (2011) The scholarship of researcher development: Mapping the terrain and pushing back boundaries. International Journal for Researcher Development, 2, 75-98.

Evans, L. (2012) Leadership for researcher development: What research leaders need to know and under- stand. Educational Management Administration and Leadership, 40(4), 423-435.

Field, A. (2009) Discovering statistics using SPSS (3rd ed.). Thousand Oaks, CA: SAGE.

Gelso, C. J., Baumann, E. C., Chui, H. T., \& Savela, A. E. (2013) The making of a scientistpsychotherapist: The research training environment and the psychotherapist. Psychotherapy, 50, 139-149.

Halabi, J. O., \& Hamdan-Mansour, A. (2010) Attitude of Jordanian nursing students towards nursing research. Journal of Research in Nursing. Advance online publication 3 September. doi:10.1177/1744987110379782.

Howitt, D., \& Cramer, D. (2014) Introduction to research methods in psychology (4th ed.). London, England: Pearson. 
Hu, L. T., \& Bentler, P. M. (1999) Cut-off criteria for fit indexes in covariance structure analysis: Conventional criteria versus new alternatives. Structural Equation Modeling, 6(1), 1-55. Retrieved from http://dx.doi. org/10.1080/10705519909540118

International Education Association of South Africa (IEASA). (2009) Study South Africa: The guide to South African higher education (9th ed.). Pretoria, South Africa: IEASA.

Laher, S., Israel, N., \& Pitman, M. (2007). Teaching research and statistics at undergraduate level: The RDA tutorial programme. South African Journal of Psychology, 37, 368-374.

Mehrdad, N., Salsali, M., \& Kazemnejad, A. (2008) Iranian nurses' attitudes toward research utilisation. Journal of Research in Nursing, 13, 53-65.

Muthén, L. K., \& Muthén, B. O. (2012) Mplus user's guide (7th ed.). Los Angeles, CA: Muthén \& Muthén. Ozturk, M. A. (2011) Confirmatory factor analysis of the educators attitudes toward educational research scale. Educational Sciences: Theory and Practice, 11, 737-747.

Papanastasiou, E. C. (2005) Factor structure of the 'Attitude toward Research' scale. Statistics Education Research Journal, 4, 16-26.

Papanastasiou, E. C., \& Schumacker, R. (2014) Rasch rating scale analysis of the attitudes toward research scale. Journal of Applied Measurement, 15, 189-199.

Papanastasiou, E. C., \& Zembylas, M. (2008) Anxiety in undergraduate research methods courses: Its nature and implications. International Journal of Research and Method in Education, 31, 155-167.

Rezaei, M., \& Zamani-Miandashti, N. (2013) The relationship between research selfefficacy, research anxiety and attitude toward research: A study of agricultural graduate students. Journal of Educational and Instructional Studies, 3(4), 69-78.

Roberts, L. D., \& Povee, K. (2014a) A brief measure of attitudes towards mixed methods research in psychology. Frontiers in Psychology, 5, 1312.

Roberts, L. D., \& Povee, K. (2014b) A brief measure of attitudes towards qualitative research in psychology. Australian Journal of Psychology, 66, 249-256.

Schreuder, D., \& Coetzee, M. (2010) An overview of industrial and organisational psychology research in South Africa: A preliminary study. SA Journal of Industrial Psychology, 36, \#903 (11 pp.).

Schulze, S. (2009) Teaching research methods in a distance education context: Concerns and challenges. South African Journal of Higher Education, 23(5), 992-1008.

Schulze, S. (2010) Mentoring to develop research self-efficacy, with particular reference to previously disadvantaged individuals. Koers, 75, 429-451. 
Selaledi, D. (2009) Building research capacity at CUT (professional growth and development). Interim: Interdisciplinary Journal, 8, 80-88.

Siemens, D. R., Punnen, S., Wong, J., \& Kanji, N. (2010) A survey on the attitudes towards research in medical school. BMC Medical Education, 10, 4. Retrieved from http://www.biomedcentral.com/1472- 6920/10/4 SPSS 20.0 (computer software) (2011) Chicago, IL: SPSS, Inc.

Steyn, H. S. (1999) Praktiese betekenisvolheid: Die gebruik van effekgroottes [Practical significance: The use of effect sizes]. Wetenskaplike bydraes - Reeks B, Natuurwetenskappe Nr. 117. Potchefstroom, South Africa: PU vir CHO.

Van der Westhuizen, S. (2014) Postgraduate students' attitude towards research, their research self-efficacy and their knowledge of research. South African Journal of Higher Education, 28(4), 1414-1432.

Walker, D. A. (2010) A confirmatory factor analysis of the attitudes toward research scale. Multiple Linear Regression Viewpoints, 36, 18-27. 